\title{
Níveis de significação: questões epistemológicas em torno das interações discursivas
}

JAIRO FERREIRA Universidade do Vale do Rio dos Sinos / UNISINOS 


\section{Resumo}

Neste artigo, definimos a significação como um processo não só lingüístico, mas também como um processo ancorado no conjunto da ação, incluindo as formas de pensamentos representativos anteriores ao próprio discurso. Buscamos uma abordagem epistemológica para as relações entre prática, representação e discurso que permita problematizar as articulações entre condutas discursivas e nãodiscursivas na perspectiva da produção social do sentido. Nosso objeto central é pensarmos a produção de conhecimento social incluindo o especificamente discursivo, buscando, ao mesmo tempo, elementos para uma epistemologia dos processos midiáticos que considerem a singularidade discursiva. Para viabilizar esta abordagem, o artigo propõe uma síntese entre os processos de significação enumerados pela análise de discurso que escolhemos (Charaudeau) e os processos de significação sugeridos na teoria genética (Piaget).

\section{Palavras-chave}

epistemologia, discurso, significação

\section{Abstract}

In this article, we define the signification not just as a linguistic process but also as a process anchored to the set of action, including the ways of representative thinking, anterior to the discourse itself. We searched for an epistemological approach to the relations between practice, representation and discourse that allows a questionable state around the articulations between the discursive and non-discursive conducts, in a perspective of the meaning social production. Our aim is thinking the social knowledge production, including the specifically discursive, searching for, at the same time, elements to an epistemology of mediatic processes, which consider the discursive singularity. In order to make possible this approach, the article proposes a synthesis between the specified signification processes by the chosen discourse analysis (Charaudeau) and the suggested signification processes in the genetic theory (Piaget).

\section{Key words}

epistemology, discurs, signification 


\section{Questões em jogo}

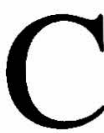

om a discussão sobre significação prática, representativa e discursiva, queremos situar os limites da análise do discurso para a compreensão do conjunto das significações em produção, interpretação e circulação entre os sujeitos interlocutores. Em certa medida, justificamos a importância da observação direta (proposta pela etnometodologia) para a análise da produção social de sentido.

Aceitamos, aqui, a tese de Piaget, segundo a qual a significação é um universo vinculado ao conjunto das interações. Nesse sentido, a significação é mais ampla do que aquela que emerge especificamente das interações através de atos de linguagem. A ausência do discurso, para a psicologia genética, não implica ausência de significação das interações, já que esta poderá ocorrer em torno da própria significação prática e de formas representativas (concretas e inconscientes), anteriores ao discurso.

A perspectiva de que a significação ocorre em três níveis (prático, representativo e discursivo) nasce de duas críticas. Por um lado, a psicologia genética, que sempre analisou o dito num quadro em que compara as significações através da linguagem com a significação implicada nas interações concretas (representativas e práticas, conceitos que veremos adiante). Ou seja, Piaget nunca verificou sistematicamente como o dito abre novas questões, específicas do processo discursivo, no campo da significação (inclusive porque 
seu objeto eram as operações cognitivas, e não, a significação em geral). É, nesse sentido, que recorremos à análise do discurso (conforme Charaudeau, 1983), porém transformando esta análise naquilo que ela é, atravessada pelas questões cognitivas. Isto é, sugerimos que, em dispositivos de comunicação, as interações entre sujeitos estão marcadas pelos atos de linguagem, os quais implicam um processo de significação específico. Assim, se a tese de Piaget nos parece válida mesmo quando estamos investigando interações entre adultos, pensamos que ela não dá conta dos processos de significação em sua particularidade discursiva. Mas, por outro lado, podemos afirmar o inverso em relação às teorias do discurso, quando tentam esgotar a problemática da significação nos atos de linguagem e de fala.

\section{Ação e interação}

Piaget, em sua formulação, mesmo quando fala de interações entre adultos, considera que a ação antecede a consciência, apesar de os mais velhos já terem atingido os níveis operatórios, concretos e formais, incluindo a competência de projetos de atos de linguagem. Nesse aspecto, Piaget se alinha com teóricos como Marx e Bourdieu na sociologia. Diz ele:

... o defeito comum da maior parte das explicações sociológicas é ter querido de antemão constituir uma sociologia da consciência ou mesmo do discurso, enquanto na vida social, como na vida individual, o pensamento procede da ação e uma sociedade é essencialmente um sistema de atividades, cujas interações elementares constituem, no sentido próprio, em ações se modificando uma às outras, segundo certas leis de organização ou de equlíbrio: ações técnicas de fabricação ou de utilização, ações econômicas de produção e de repartição, ações morais e jurídicas de colaboração ou de coação e opressão, ações intelectuais de comunicação, de pesquisa em comum ou de crítica mútua... É na análise destas interações no comportamento mesmo que procede então 
à explicação das representações coletivas, ou interações modificando a consciência dos indivíduos (Piaget, 1973, p. 34, o grifo é nosso).

Esta tese pode ser interpretada como uma negação do valor do discurso no processo de significação. Porém, preferimos outra leitura, em que vislumbramos uma porta para o que sugerimos: se a comunicação é uma ação, trata-se de compreender a significação no interior das interações que nascem desta ação, o que, em nọssa perspectiva, é formulado especificamente pela análise do discurso (apesar de que existam outras contribuições de estudos da comunicação que também vão estudar estes processos de significação) sempre que esta ação comunicativa abranger também atos de linguagem e ordens discursivas ${ }^{1}$ Mas esta significação extraída - pela análise - da ação (conduta) discursiva se combina com outra, não-discursiva, também prática e/ou representativa concreta. E, ainda, esta ação deve ser inserida no conjunto da interação com os objetos e outros sujeitos.

Quando o objeto é o desenvolvimento cognitivo, o método clínico procura dar conta deste processo, inclusive comunicativo, através de um conjunto de procedimentos (observação, experimentação, entrevista clínica etc.) em interação com os sujeitos, visando a compreender o sujeito epistêmico. Na ausência do método clínico, a observação de condutas discursivas em dispositivos experimentais, permite somente aproximações às significações práticas e representativas concretas, sugeridas no quadro de conceitos piagetianos.

1. Esta questão está situada assim por Maingueneau (2001): Falar é uma formatação sobre o outro, e não apenas uma representação sobre o mundo. A problemática dos "atos de linguagem" (ou "atos de fala", ou ainda "atos de discurso"), desenvolvida a partir dos anos sessenta por filósofos como J. L. Austin (Quando dizer é fazer, 1962) e J. R. Searle (Os atos de linguagem, 1969), mostrou que toda a enunciação constitui um ato (prometer, sugerir, afirmar, interrogar etc.) que visa a modificar uma situação. Em um nivel superior, esses atos elementares se integram em discursos de um gênero determinado (um panfleto, uma consulta médica, um telejornal etc.) que visam a produzir uma modificação nos destinatários. De maneira mais ampla ainda, a própria atividade verbal encontra-se relacionada com atividades não-verbais. Esta formulação, entretanto, situa no mesmo plano o que é representações práticas, concretas e discursivas, abstraindo as condições específicas do dispositivo. 
Propomos que as significações sob este recorte do cognitivo podem ser confrontadas com os possíveis sentidos traçados pela análise do discurso, evidenciando diversas relações sociais e de sentido ausentes na pesquisa epistemológica. Nessa perspectiva, o cognitivo, o social e a linguagem podem ser revelados nas suas relações mútuas (Ferreira, 2002b).

Afirmar que a significação está ancorada no conjunto da ação pode resultar numa concepção unívoca dos processos de significação que queremos desenvolver. Porém, pensar a ação no interior do conjunto das interações implica em compreender que a ação não é unívoca (do tipo $\mathrm{A} \rightarrow \mathrm{B}$ ) e sim, é parte das interações dos sujeitos entre si e destes com os objetos (do tipo $\mathrm{A} \leftarrow \rightarrow \mathrm{B}$ ). Consideramos, aqui, a formulação de Piaget em A Tomada de Consciência (1974). Nesse caso, a significação - por parte dos sujeitos envolvidos - é um processo que se desenvolve a partir dos aspectos mais visíveis das interações, que chama de periferia (p), ponto imaginário que capta parte da ação (as finalidades do ato) e do objeto (os resultados esperados). Este é o marco zero do processo de significação de qualquer interação, e sua existência atesta a impossibilidade de uma interação sem um mínimo de referência de significação tão logo o sujeito tenha constituído um universo de pensamento representativo. A significação que nasce dos mecanismos externos (finalidade da ação e resultados esperados relativamente ao objeto da ação) da interação, caminha no sentido dos mecanismos internos dos dois aspectos das interações (ação e objeto). Esquematicamente: a interação $S \leftarrow \rightarrow$ $\mathrm{O}$ é compreendida a partir do ponto $\mathrm{P}$, intermediário da interação, conforme o esquema $\mathrm{S} \leftarrow \mathrm{P} \rightarrow \mathrm{O}$. A pesquisa entre os dados observados na transformação pretendida e realizada do objeto e, correlativamente, da ação, seja no sentido do insucesso (por que o ato não gerou o resultado?), ou da atualização das finalidades (novos esquemas de assimilação do objeto, permitindo a comparação de resultados), é que permite a compreensão de um e outro (e nem um, nem outro, ação ou objeto, isoladamente). Sob esse aspecto, a significação é um processo, que se desenvolve no sentido de compreensão da própria ação e do objeto desta ação. 


\section{Fontes teóricas do conceito de níveis ${ }^{2}$}

Nossa formulação parte de alguns recortes. Primeiramente, compreendemos a questão da significação no interior das relações entre prática e pensamento representativo. A representação, como $\operatorname{diz} S f e z$, nasce com a diferenciação entre representante (significante, em Saussure, esquemas de acomodação, em Piaget) e representado (significado, em Saussure, esquemas de assimilação, em Piaget). Para falarmos assim é necessário esclarecer: primeiro, não estamos investigando a gênese do conhecimento em crianças; segundo, toda a inferência teórica que fizermos é uma proposição que efetuamos no sentido de compreender a significação como constituinte da produção de conhecimento na vida social, e não o restrito processo psicológico; terceiro, sugerimos a reconstrução da análise sugerida por Charaudeau para elucidar o momento específico da significação e cognição, vinculado ao discurso.

O estudo da significação a partir de Piaget requer, antes de tudo, a referência aos conceitos de assimilação e acomodação. A dialética geral do funcionamento do pensamento nascente se desenvolve em torno das interações entre estes dois processos fundamentais. Por assimilação, compreende-se a modificação objetiva dos movimentos e posições externas pelos movimentos próprios, bem como a modificação subjetiva que resulta do fato de que a percepção ou a compreensão desses movimentos e posições externos é necessariamente relativa ao "ponto de vista" próprio (Piaget, 1975, p. 347). Por acomodação, entende-se a modificação

2. Este artigo retoma questões abordadas em artigos anteriores e na minha tese de doutorado. O interesse dessa articulação entre vincula-se a um objeto que queremos construir a partir da seguinte questão: como o discurso se insere na produção social do conhecimento? Consideramos que essa questão nos remete ao tema "epistemologia e discurso". No campo da comunicação, esse tema é próximo ao estudo das relações entre discurso e cognição (Van Dijk, 1999), e no espaço de discussāo sobre as relaçōes entre signo e cogniçāo (revisada por Peraya: 1995, 1998, 1999). Vincula-se também ao tema discurso e conhecimento (Verón), midia e conhecimento (Meunier, 1999) e aproxima-se da temática da comunicação e educaçāo. Procuramos, em particular, uma formulaçāo que nos permita interpretar os produtos discursivos (textos, imagens, sons, gráficos, articulados entre si) enquanto proposições de saber. 
dos movimentos e do ponto de vista próprios pelos movimentos $e$ posições exteriores (Piaget, 1975, p. 348) e três possibilidades limites: a primeira, de equilíbrio entre assimilação e acomodação dos esque$m a s^{3}$ de significação ao real; a segunda, de a assimilação ser predominante no processo de significação; terceira, de a acomodação ser predominante. Na medida em que assimilação e acomodação são expressões de esquemas do sujeito, as duas atividades funcionais supõem a existência e transformação dos esquemas de assimilação. Por isso, Piaget fala em acomodação dos esquemas assimiladores (Piaget, 1975 , p. 365) quando menciona a imitação infantil, ou quando afirma que não existe acomodação em estado puro (Piaget, 1974), já que está sempre vinculada a um esquema de assimilação.

Propomos uma interpretação tipicamente hegeliana deste conceito de equilíbrio em Piaget, que nos remeta não apenas à relação em que tese, antítese e síntese se sucedem de forma circular ascendente, mas ao constante movimento de superação em que o nível posterior conserva, nega e amplia o anterior. Um círculo que pensamos como não-homogêneo, com momentos predominantes (Lukács, 1979, p. 94), que nos permitem pensar a assimilação ou a acomodação como predominantes, absorvendo o pólo oposto. Em nossa interpretação, falar em relação dialética e de predominância entre os dois esquemas funcionais implica a inexistência de um sem o outro, ou em cada um existindo necessariamente com outro, em equilíbrio ou não. $O$ equilíbrio é, aqui, um dos grandes indicadores do que o autor considera atividade inteligente, num processo sempre permeado de novos desequilibrios.

Queremos, ainda, com o conceito de dialética, referir-nos à questão da dominância e da contradição. Fausto (1983) acentua que a contradição que a dialética acolhe no princípio de identidade (ser e não ser simultaneamente) não é exatamente aquele que a lógica formal recusa (Fausto, 1983, p. 153). Este autor sugere uma interpretação que destaca, na dialética das significações, as zonas de sombra, que contêm um halo escuro relativo às intenções não-preenchidas. Para

3. Utilizamos, aqui, o termo esquema apesar da diferença existente em francês entre o schème e o schéma. O primeiro é relativo a uma categoria piagetiana, originada na filosofia kantiana. O segundo refere-se ao nosso esquema. 
a dialética, trata-se, entretanto, de intenções que não podem nem devem ser preenchidas. Há um campo de intenções que deve se conservar como campo de intenções (Fausto, 1983, p. 150). Colocase, aqui, a dialética entre o obscuro e o claro, o pressuposto e o posto, o não-dito e o dito, o implícito e o explícito.

A idéia de que a significação vincula-se ao conjunto da ação é uma das chaves do pensamento piagetiano. Na gênese infantil, antes da linguagem, a significação ocorre no curso da própria ação sensória-motora, utilizando-se, com o desenvolvimento, do índice e do sinal (inclusive no quadro de condicionamentos como é proposto pelo behaviorismo) como significantes que informam sobre parte do objeto e da ação, e não, sobre o conjunto (mesmo que possam desencadear um conjunto de ações por parte do sujeito que assim significa o real). $\mathrm{O}$ aspecto figurativo (que, em nossa interpretação, vincular-se-á às formas simbólicas e referenciais do pensamento representativo, isto é, significados e significantes) começa a se diferenciar através da configuração das percepções, que se desenvolvem no contexto de um conjunto de condutas em que o sujeito elabora as formas, a constância, o objeto permanente e os efeitos de campo.

Porém, este aspecto figurativo do pensamento representativo encontra-se, na gênese, vinculado a processos mentais associados à ação imediata, sensório-motora, sem expressão diferenciada desta, ao mesmo tempo em que ação e percepção são irredutíveis uma em relação à outra (Piaget, 1982, p. 33). Esses processos atestam a indiferenciação entre significantes e significados, ou seja, o significado da ação é, ao mesmo tempó, o seu significante, inclusive quando são esboçados os esquemas perceptivos (Piaget, 1982; 1975).

Este é o momento das categorias práticas, em que a significação é sensório-motora, isto é, não tem antecipações típicas do pensamento representativo, o qual se caracteriza por mobilizar significantes e significados, diferenciados sempre que uma ação imediata de interação com objetos se desenvolve. Em nossa proposição, mesmo adultos, continuamos a desenvolver uma parte de nossas interações sob as formas de significação prática. Isto é, muitas vezes só diferenciamos os objetos de outros conhecidos anteriormente através da ação. Porém, em geral, esta ação vai evocar representações 
construídas senão sobre o novo objeto, mas em torno de seus similares, representantes ou tipos genéricos. Nesse sentido, o pensamento prático nos adultos se desenvolve em torno de um novo núcleo, o do pensamento representativo. Nas franjas deste pensamento representativo, a ação retorna ao escopo do pensamento prático, sensório e motor, em que a significação se constitui no âmbito do imediato já que tem lacunas em termos de antecipação figurativa ou operativa (como no exemplo que veremos sobre uma conversa telefônica sobre como anexar um arquivo com a ferramenta de e-mail do Netscape).

A dissociação das percepções da própria ação vai corresponder ao desenvolvimento do pensamento representativo (mesmo que concreto). Temos, aqui, uma diferenciação da atividade sensória e motora que, do ponto de vista do desenvolvimento da função semiótica (Piaget, 1982), permite um salto na medida em que o aspecto figurativo do pensamento se emancipa das ações e objetos imediatos. Porém, se as percepções (forma, grandeza, objeto permanente etc.) são estruturas figurativas, conforme a concepção da Gestalt, tais estruturas - para Piaget são construídas e transformadas pelas ações sobre o real. A demonstração desta relação entre percepção e ação vai ser fundamentada, em Piaget (1991), numa pesquisa realizada por um dos teóricos da Gestalt, Ivo Köhler, que demostra como a motricidade altera a percepção invertida da realidade (feita através de óculos com lentes de 180 graus), e a coordenação da ação - do ciclista - passa a responder não à percepção primeira - do mundo invertido com os óculos -, mas àquela reconstruída pela ação sensória e motora.

Na medida em que a significação deixa de ser sensório motora, as interações passam a incidir não só sobre os dados atuais, mas também sobre os próprios significantes diferenciados em construção já a partir da percepção. Ou seja, como afirmamos, as interações presentes remetem às representações evocadas, transformando-as. Este o é elo no qual nasce o pensamento representativo, que se caracteriza

pelo fato de que os objetos não atualmente perceptiveis aos quais é assimilado o objeto percebido são evocados graças a "significante" que os torna presentes ao pensamento, na ausência de uma presença real. A representação 
nasce, portanto, da união de "significantes", que permitem evocar os objetos ausentes com um jogo de significação que os une aos elementos presentes (Piaget, 1975, p. 351).

Como veremos no exemplo abaixo das interações através do dispositivo telefônico, as interações se desenvolvem com interlocutores que possuem níveis diversos de significação (um com significação concreta e funcional; outro, condicionado pelas significações práticas; os dois, com dificuldades na esfera da significação discursiva).

\section{Significações práticas, representativas e discursivas}

Os conceitos, que desenvolvemos, de interações práticas $e$ representativas são inspirados nos conceitos de categorias práticas e representativas 'do pensamento em Piaget (1975). As interações discursivas, em nossa análise, serão compreendidas conforme a proposta desenvolvida pela análise de discurso (especificamente, Charaudeau, 1983), com algumas modificações. A primeira destas modificações é a de que a significação está inserida na própria dialética entre os três níveis. Assim, as condutas discursivas estão contidas nos universos de significação vinculados às categorias práticas e representativas, ao mesmo tempo em que são reconstruções dos processos anteriores de significação.

Se abstrairmos as transformações emergentes dos dispositivos midiáticos, afirmamos que a análise das interações em dispositivos de comunicação se desenvolva nos seguintes níveis de significação:

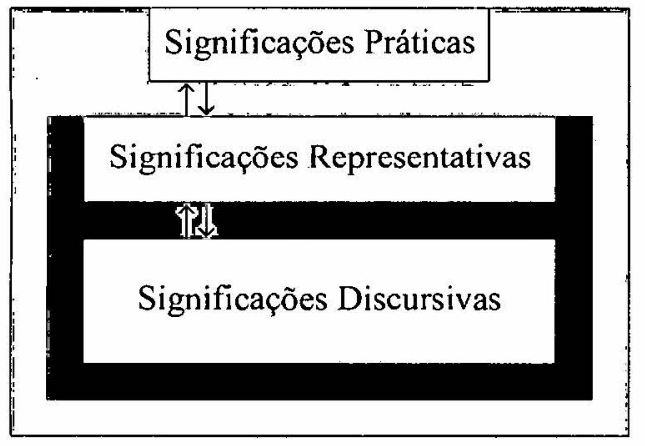

Figura 1 - Os niveis de significaçāo 
Para compreendermos essa proposição:

A significação prática abrange os sentidos, as percepções e a ação. Os quadros perceptivos constituídos nessa esfera são « colados » à presença dos objetos, ao mesmo tempo em que começam, através das estruturas figurativas (de continuidade, figura de fundo, constância, grandeza etc.) a se liberar dos objetos e situações em sua materialidade. Esse nível corresponde ao pensamento intuitivo ${ }^{4}$.

A significação representativa concreta é resultante de relações entre vários quadros perceptivos e se expressa na ação e percepções reconstruídas (na medida em que os quadros são relacionados). Assim, no nível da significação concreta, o sujeito "sabe" que as laterais de uma estrada não se encontram no infinito como sugere a percepção visual. $O$ sujeito operativo relaciona esse quadro figurativo - das laterais que se tocam - com as relações construídas - as paralelas não se tocam -. Ele antecipa que o encontro das laterais é uma percepção falsa do real. Esse nível corresponde ao pensamento operatório concreto .

A significação representativa discursiva requer a constituição da linguagem em suas várias modalidades (analógicas, digitais, formais etc.) e dimensões (linguísticas, discursivas e situacionais). $O$ discurso retoma a intuição e a significação concreta, em diferentes graus de proximidade, com os fluxos discursivos estruturados pelos campos sociais.

Sugerimos, aqui, a metáfora do edifício: os níveis se referem aos andares; as formas de significação (o referencial, o lógico, o

4. O próprio do esquema sensório-motor (percepção etc.), do símbolo preconceitual, da configuração intuitiva, é que eles são sempre "centrados" sobre um estado particular do objeto e um ponto de vista particular do sujeito; eles sempre testemunham, pois, simultaneamente, uma assimilação egocêntrica do sujeito ou uma acomodação fenomenista ao objeto (Piaget, 1967, p. 152).

5. O próprio do equilibrio móvel que caracteriza o agrupamento é, ao contrário, que a descentração, já preparada pelas regulações e articulaçōes progressivas da intuição, chega, sistematicamente, a um novo patamar : então, o pensamento não se liga mais aos estados particulares do objeto, mas passa a atingir as transformaçōes sucessivas, segundo todas as suas idas e vindas possiveis; e, ele não procede mais de um ponto de vista particular do sujeito, mas coordena todos os pontos de vistas distintos em um sistema de reciprocidades objetivas (Piaget, 1967, p. 152). 
funcional e o simbólico que atravessam o discurso) são as faces laterais desse edifício. Assim, cada nível (andar) tem quatro faces. É necessário fazer quaisquer observações sobre essa proposição.

Primeiro, no nível da significação prática, afirmamos, não há diferenciação. O conceito de imaginário expressa essa indiferenciação. Ele emerge da confluência, indiferenciada, entre os diversos níveis de significação. No imaginário, o eu e o outro confluem, expressando o caráter fusional entre sujeito e objeto, que identificamos no conceito de significação prática. Nesse nível, a imitação (que é relativa à significação que conceituamos de referencial) oscila entre a ausência e presença das representações, na medida em que a representação só se afirma com a diferenciação entre o eu e o outro (que pode ser outro sujeito e/ou objeto), ou - como propõe Saussure - com a diferenciação entre os significados e os significantes. Nesse nível há, portanto, uma indiferenciação entre as várias faces (esse entrelaçamento entre as faces de significação na gênese aparece com evidências no mito - em que lógica, referencialidade, funcionalidade e simbolização estão justapostas como valores idênticos).

Mesmo quando a imitação atinge as representações típicas do pensamento prático, sua presença atesta a oscilação em fases anteriores à reflexão. Assim, sabemos, há uma diferença entre a imitação que se expressa em representação refletida (quando operamos e produzimos quadros perceptivos antecipados que "enxergam" paralelas para além das laterais da estrada que se tocam), e a imitação como representação dessas laterais como linhas que se tocam. efetivamente (quando o conceito de perspectiva não opera). Na medida em que a significação prática é pré-operatória, ela sempre será uma representação deformada do real (que pode ser físico e social), ao mesmo tempo em que é, geneticamente, uma das fontes da significação concreta e formal ${ }^{6}$. Porém, na medida em que a prática -

6. Não por acaso Cremilda Medina, ao discutir epistemologia do jornalismo, vai propor uma interaçāo direta do jornalista com a sociedde, que mobilize os sentidos, sem mediação tecnológica. Sua formulação aponta para a importância da significação prática como nível genético de renovação social do pensamento. 
ação, sensações e quadros perceptivos - são diferenciados pelos níveis de significação concreta e formal, a dimensão deformante se dissolve nas operações de ressignificação do mundo.

Segundo, o nível da significação concreta se refere ao inconsciente social que opera sobre o mundo (como no caso em que a noção concreta de perspectiva permite que se anda em direção às linhas que se tocam), mas sem expressão discursiva lógica e operatória. Bourdieu (1990) falará em prática para se referir a esse nível. Entretanto, a definição de apenas um nível (a prática) para a ação social sem fundamentos racionais cria um problema epistemológico relativo aos níveis de ação que carecem de uma lógica da ação, e se fundamentam em intuição, sensações e percepções. "Sentir a realidade" se refere ao nível da prática, e portanto sempre se "articula" com um determinado nível de ação e percepção da realidade. Aqui se encontra o pensamento social intuitivo (presente também no mito e no rito). Já os esquemas e estruturas mobilizados inconscientemente referem-se a significação concreta que transforma a ação, a percepção e as sensações em decorrência da ativação dos esquemas racionais inconscientes. Entre percepções imediatas da realidade e as percepções fundadas pelos esquemas representativos concretos há uma dialética comandada pelo conjunto da ação. Isso explicaria porque o mito já apresenta vários esquemas que, após diferenciação e integração em novas totalidades, vão fundar a lógica, a arte, a política e o fato.

Nesse sentido, o termo concreto não conduz a uma identificação do mundo físico e/ou da face referencial do signo. Como sabemos, existem signos que não podem se referir a um mundo físico, na medida em que a referência do signo pode estar ligada ao mundo social. Isso quer dizer que termos como liberdade, igualdade, impossível, moral e tantos outros são também construídos com diversos níveis (mãos ou menos abstratos) de relação com a ação social (mesmo se tal ação é um movimento do pensamento). Nos dois casos - referência do sino ao mundo físico ou social -, falamos da forma referencial do signo. A dimensão concreta não se refere a essa forma.

Portanto, significação concreta não se refere ao referencial, ao real. O concreto se refere ao subjetivo individual e social que não 
se revela no discurso, mas que está presente nas ações e interações, inconscientemente (e nesse sentido, o não se revelar, aqui, é diverso da dissimulação), expressando uma lógica da ação.

Terceiro, a significação discursiva emerge da singularidade do próprio discurso. É a dimensão de revelação, de explicitação das ações e interações, através das diversas linguagens. Através do discurso, o sujeito se libera da ação imediata e singular que o caracteriza para "enfrentar-se" com outras significações, de outros sujeitos, às quais permitem um redimensionamento do conhecimento anterior, na medida em que se desloca do âmbito da ação individual. A dimensão discursiva do conhecimento é retratada com brilhantismo por Verón (1981) em de seus textos, quando discute o conhecimento científico.

\section{Interações entre sujeitos}

Mas como compreender as interações entre os sujeitos? Nossa proposição é a de que entre os sujeitos, as trocas se desenvolvem em torno de objetos (materiais e imateriais), que são transformados pelas ações de cada um dos interlocutores, na forma de proposições que são aceitas parcial ou totalmente, ou refutadas e negadas através de outras proposições. Esta formulação indica que as interações entre os indivíduos são complexas. Os sujeitos envolvidos devem significar a própria ação e transformações dos objetos que sugerem, mas também as dos interlocutores, incluindo a coordenação e validade dos objetos implicados nas trocas.

Se consideramos as formulações de Charaudeau, nas interações entre sujeitos emergem múltiplos objetos: objetos de conhecimento e reconhecimento e os "eus" internos e externos aos atos de fala. Não se trata, portanto, de interações restritas aos objetos de conhecimento, de que trata o embate moderno sobre as relações entre sujeito e objeto. Nas interações discursivas, eclodem diversas dimensões objetais.

Portanto, os processos de significação prática, representativa e discursiva referem-se ao conjunto de ações (condutas e procedimentos) e objetos inseridos nas trocas interindividuais. Esta significação começa pelo jogo de intenções (da ação) e resultados (de 
transformação dos objetos materiais e imateriais), podendo atingir a compreensão do núcleo das ações e dos objetos das interações.

\section{Uma ilustração de trocas via telefônica}

Exemplo: ilustraremos este recorte duplo, tomando uma situação relativa ao que consideramos como conhecimento funcional (Ferreira, 2002a, 2002b). Contaremos, aqui, um caso particular em nossa experiência através de uma interação, via telefone. Recentemente, necessitamos de que um artigo fosse enviado, anexado em e-mail, para um endereço qualquer em que nos encontrávamos. A pessoa que deveria enviar tinha acesso ao computador, mas não detinha o conhecimento do mecanismo de como anexar arquivo no e-mail, utilizando o Netscape. De onde estávamos, não tínhamos acesso imediato a um computador. Utilizando o telefone, ligamos para nosso interlocutor e passamos a orientá-lo. As orientações preliminares foram fáceis: clicar em iniciar, depois em programas, escolher Nestcape e ferramenta de e-mail. Aberta a ferramenta, prosseguimos, já com dificuldades, para a abertura de novas mensagens na ferramenta de $e$-mail. Conseguimos. Colocado o endereço, o passo seguinte era o de anexar. Nesse momento, lembramos do comando anexar, mas não tínhamos consciência do que ocorria com a ferramenta depois de clicar em anexar. Interagimos com o nosso colaborador e descobrimos os comandos possíveis (arquivo, página web ou cartão). Pedimos para clicar em arquivo. Novamente, um impasse: não tínhamos consciência do que aparecia posteriormente. $\mathrm{O}$ nosso interlocutor não soube explicar quais as possibilidades de interação com a tela (aparece uma tela, que não víamos, pedindo que seja digitado o arquivo a ser anexado; porém, este arquivo deve ser procurado no lugar onde se encontra - disco rígido, disquete no drive etc.). Depois de várias tentativas para encontrar um caminho via conversa telefônica, desistimos. Procuramos um computador, onde pudéssemos orientar passo a passo, olhando a tela, ou seja, tendo como referência o contexto gráfico e visual da ferramenta de e-mail do Netscape. 
Na medida em que, há muitos anos, trabalhamos com as ferramentas de e-mail do Netscape, utilizando-as sem nenhuma dificuldade funcional, a experiência acima demonstra que os elementos discursivos que mobilizamos não correspondiam aos procedimentos que conhecíamos em termos representativos concretos. Ou seja, nossa competência em anexar um arquivo numa mensagem estava circunscrita à própria ação concreta. Carecia de uma representação discursiva passo a passo, até atingir o sucesso funcional pretendido. Carecia, portanto, de uma estruturação discursiva. Porém, como saber-fazer, nossa ação já atingia níveis de sucesso funcional (na medida em que, há alguns anos, desenvolvemos esta conduta sem dificuldades). Por outro lado, a interação demonstrou que nosso interlocutor não havia ainda atingindo a competência funcional em torno do ato de anexar um arquivo num e-mail. Como a competência de nosso interlocutor não atingira o nível discursivo de enunciar quadro a quadro de imagens através do dispositivo telefônico, foi impossível orientá-lo para o sucesso funcional na interação.

No caso acima, temos uma ilustração de como a transposição da significação prática e representativa concreta para um dispositivo é um processo complexo. Mas ela é apenas a ponta de iceberg das dificuldades colocadas pelas interações em dispositivos de comunicação. $\mathrm{O}$ exemplo acima é de dois sujeitos que interagem em torno de um objeto visível (no caso, um objeto material), isto é, as interações discursivas combinaram-se com outras formas de ação (prático e representativas), no sentido de que cada ação enunciada em atos de linguagem era confrontada com as transformações do objeto (no caso, a ferramenta de e-mail: o que aconteceu? Ou aconteceu isto ou aquilo...), certamente mediadas por representações outras, mobilizadas pelos interlocutores, mas ausentes da linguagem própria ao dispositivo (telefônico) utilizado. Estas interações eram retomadas através dos atos de linguagem, até o limite em que as dificuldades em representar em palavras as imagens e transformações do objeto impedirem o prosseguimento, com sucesso, das intenções dos sujeitos e resultados esperados (anexação de um arquivo). Consideramos, em nossa proposição, que este caso simples de interações é um caso particular de qualquer tipo de interação 
entre dois sujeitos, inclusive quando se trata de objetos imateriais. Mas, no caso dos objetos imateriais, os interlocutores passam a depender de operações abstratas e formais.

De qualquer forma, nos dois casos, tanto do ponto de vista da interpretação como da produção, a significação não está contida apenas nos limites das práticas discursivas. A outra face é a de que as interações desenvolvidas através da rede ou do telefone estão ordenadas pelo discurso, isto é, as interações se desenvolvem condicionadas pelos atos de linguagem (incluindo o saber sobre as práticas e representações não-discursivas). A tese que desenvolvemos visa a responder e a enriquecer as interpretações possíveis, identificadas através das duas perspectivas. É nesse sentido que diferenciamos as categorias práticas, representativas e discursivas.

\section{Conclusões}

Através de uma situação de interação, procuramos as evidências que demonstram que a riqueza de significação que podemos extrair das interações via discurso não responde - em nossa perspectiva - a questões da significação extralingüística, impossíveis de serem resolvidas inclusive no campo da interpretação. Vamos nos referir a algumas destas questões na análise da sequiência acima. Referenciados na dialética entre significação prática, representativa concreta e discursiva, podemos afirmar que os limites impostos pelo dispositivo à significação perceptiva e via atos sensoriais e motores 'olhar', 'escutar', 'tatear', 'cheirar' diretamente - não foram compensados pelas formas de pensamento representativo em atos de linguagem. Sob esta ótica, parece-nos evidente que o habitus ${ }^{7}$ das interações está configurado, em grande medida, nessa forma de

7. O habitus (Bourdieu) sāo as formas de percepção, pensamento e ação coletivos, que perpassa as formas de subjetividade individuais, e irão se refletir nos sistemas operatórios e classificatórios sobre o que é legítimo e ilegítimo, do que é verdade e mentira, do que é belo e feio, do mal e do bem, dentro de determinado campo. Assim, Bourdieu vai se referir - por exemplo - ao fato de que cada palavra será significada diferenciada conforme habitus de quem produz e interpreta. Este conceito nos informa que toda a interação social em torno de um objeto de conhecimento nāo é neutra, mas socialmente demarcada, e incorporada às práticas. 
significação pré-linguística, na qual o dito é preenchido por percepções e atos sensoriais e motores.

Acreditamos que essa formulação permite reequacionar o lugar da percepção na produção social do signo. Peraya (1995) cita Umberto Eco, para afirmar que os ícones não possuem a propriedade dos objetos representados, mas reproduzem certas condições da percepção comum sobre a base de códigos perceptivos normais e por seleção de estímulos que - eliminando outros estímulos - permitem a construção de uma estrutura perceptiva (Eco, 1970 , p.14). Nesse sentido, se há correlação de propriedades do signo com qualquer coisa, esta ocorre não em relação ao objeto, mas com o modelo perceptivo do objeto. Dito de outro modo, Eco situa a relação analógica não entre a representação - o signo icônico - e o objeto representado - objeto real -, mas sim, entre o ícone como um modelo perceptivo do objeto (Peraya, 1995). A partir desses e de outros autores, Peraya (1995) sugere o seguinte esquema para representar a analogia entre objeto percebido, atividade perceptiva e imagem mental:

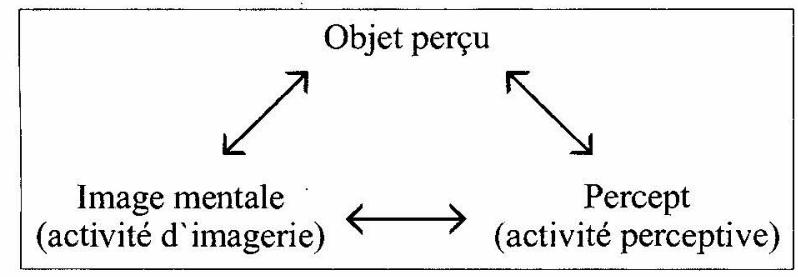

Figura 2: Relações de analogia

A diferença da formulação que desenvolvemos está no fato de que propomos uma relação de condicionamento mútuo entre os níveis da percepção, sensorial e motora, presentes nas formas de significação e conhecimento prático, através dos quais os sujeitos constroem relações com o real. Assim, o modelo perceptivo do objeto de que fala Eco é constantemente transformado pela dialética interna da significação prática do real. Essa transformação possibilita níveis superiores de consciência dos objetos e das ações humanas.

Isso equivale a dizer que o percebido não é a realidade, nem é constante; é variável e uma categoria da subjetividade, construída 
conforme o conjunto das interações, as quais implicam uma finalidade, que condiciona as próprias possibilidades de percepção. Assim, não há uma percepção, mas várias, dinâmicas, conforme as finalidades que animam as interações com os objetos, e uma das dificuldades da linguagem será sempre pretender congelar esses possíveis em imagem isolada. Neste aspecto, a imagem é uma proposição (no sentido que Verón utiliza esse termo quando fala de imagens. Conforme Peraya, op. cit.).

Como vimos, é necessário um conjunto de imagens mate-riais, encadeadas entre si, num processo lógico e/ou funcional para que essas se aproximem das imagens mentais, que construímos nas interações. Isto é, faz-se necessário compor um discurso para que as representações materiais se aproximem das significações concretas e práticas. Mas esse processo, como estamos propondo, se expressa numa nova cadeia de significações, irredutível em relação àquela das interações práticas e/ou concretas.

Uma reflexão sobre o campo dos estudos de comunicação que reforça as formulações que desenvolvemos está em Denis e de Vega (citados por Peraya, 1995). Conforme pesquisas que realizaram sobre as dimensões espaciais (alto/baixo, direita/esquerda, em frente/atrás), os sujeitos têm dificuldades diferenciadas em restituir, a partir das representações mentais (que chamamos de pensamento concreto), as diferentes relações espaciais entre os objetos em termos de linguagens. A dimensão vertical é a mais fácil de discriminar. Isso decorre, conforme a interpretação dos autores, da posição do corpo e da gravidade. A partir desses elementos, eles concluem: Os modelos mentais espaciais são orientados pelo conhecimento e pelo conjunto de experiência perceptivos e motrizes que transformam algumas dimensões mais acessiveis do que outras (M. Denis e M. de Vega, citados por Peraya, 1995). Nesse caso, falta dizer que também o nível sensorial e motor favorece "algumas dimensões mais" do que outras.

Mas isso tudo é insuficiente se não pensarmos como as sensações, intuições e percepções são inseridas no universo reflexivo concreto e discursivo. Nesse sentido, não é apenas a percepção que está imersa na cultura, mas também as formas de racionalidade concreta $\mathrm{e}$ discursiva. 


\section{Bibliografia}

BOURDIEU, Pierre. 1987. Coisas ditas. São Paulo: Brasiliense. 1990.

CHARAUDEAU, Patrick. 1983. Langage et discours. élémentes de sémiolinguistique (théorie et pratique). Paris: Classiques Hachette.

1984. Langage et société. Papier de travail. Paris: Maison des sciences de l'homme - CNRS.

1997. Le discours d'information médiatique. La construction du miroir social. Paris: Nathan.

DENIS, M. 1993. Forme imagée de la représentation cognitive. In: EHRLICH, M. F. (Ed.). Les modèles mentaux. Approche cognitive des représentations. Paris: Masson.

DENIS, M.; DE VEGA, M. 1993. Modèles mentaux et imagerie mentale. In: EHRLICH, M. F. (Ed.). Les modèles mentaux. Approche cognitive des représentations. Paris: Masson.

DUVAL, R. 1999. “Conversion et articulation des représentations analogiques". In: Séminaire de recherche 1, Direction de la recherche et du Développement, IUFM Nord Pas de Calais.

ECO, Umberto. 1970. "Sémiologie des messages visuels". Communications, 15.

1991. Tratado Geral de Semiótica. Perspectiva, São Paulo.

FAUSTO, Ruy. 1983. Marx: lógica e política. São Paulo: Brasiliense, v. 2.

FERREIRA, Jairo. 2002a. Campos de significação e conhecimento em dispositivos digitais: análise das interações discursivas em listas de discussão. Porto Alegre: Tese de Doutorado Programa de Pós Graduação em Informática na Educação - PGIE.

. 2002b. "Discurso e conhecimento: uma proposta metodológica". In: 11 Encontro anual da associação nacional dos programas de pós-graduação em comunicação, Anais do 11 COMPOS - ECO-UFRJ, 3 a 5 de junho de 2002, CD-ROM.

INHELDER, Barbel; CELLERIER, Jung. 1992. Le cheminement des découverts de l'enfant. Recherche sur les microgenèsis cognitives. Paris: Delachaux e Néstle. 
LATOUR, Bruno. 1994. Jamais fomos modernos: ensaio de antropologia simétrica [trad. de Nous n'avons jamais ete modernes]. Rio de Janeiro: Editora 34.

MAINGUENEAU, D. 2001. Análise de textos de comunicação (trad. de Analyser les textes de communication). São Paulo: Cortez.

MEDINA, Cremilda. 1991. Jornalismo e epistemologia da modernidade. In: Novo Pacto da Ciência: a crise dos paradigmas. $1^{\text {a }}$ Semana Transdisciplinar. São Paulo.

MEUNIER, Jean Pierre. 1999. Dispositif et théories de la communication: deux concepts en rapport de codetérmination. In: Hermes. Le dispositif. Entre usage et concept. Paris: CNRS editions, pp. 83-91.

PASCUAL-LEONE, Jean. 1996. Piaget, Vygotski y la función dal símbolo. Substratum, vol III, n. 8-9, pp. 63-87.

PERAYA, Daniel. 1995. "Vers une théorie des paratextes, la médiation des savoirs". Recherches en communication, 4, pp. 119-156.

. 1998. "Image(s) et cognition: Présentation du dossier". Recherches en Communication. Image(s) et cognition, 10, pp. 7-20.

1999. "Vers une sémiotique cognitive". Cognito. Revue Internationale francophone en Sciences Cognitives. Edition: In Cognito. Numero 14, pp.1-16.

PIAGET, J. 1926. A representação do mundo na criança. Rio de Janeiro: Record.

1973. Estudos Sociológicos. Rio de Janeiro: Companhia Editora Forense.

1974. La prise de conscience. Paris: Presses Universitaires de France.

1975. A formação do simbolo na criança. Rio de Janeiro: Zahar.

1991. Psicologia e Epistemologia: para uma teoria do conhecimento. Lisboa: Dom Quixote.

1996. Le structuralisme. 11.ed. Paris: Presses Universitaires de France. 
PIAGET, J.; INHELDER, B. 1982. A Psicologia da criança. São Paulo: Difel.

VAN DIJK, Teun Adrianus. 1999. Cognição, Discurso e Interação. 2.ed. São Paulo: Contexto.

VERÓN, Eliseo. 1981. A produção de sentido. São Paulo: Cultrix. . 2003. Entre la epistemología e la comunicación. In: Cuadernos de información y comunicación. Retórica. Departamento de Periodismo III. Faculdad de Ciencia de la Información. Universidad Complutense de Madrid. número 4. Disponível: http:/ /www.ucm.es/info/per3/cic/index.htm, março. 